\title{
A TESSITURA DE UM PROJETO DE FORMAÇÃO DE PROFESSORES: EDUCAÇÃO DAS RELAÇÕES ÉTNICO-RACIAIS
}

THE ORGANIZATION OF A TRAINING PROJECT FOR TEACHERS: EDUCATION OF RACIAL AND ETHNICAL RELATIONSHIPS

LA ORGANIZACIÓN DE UN PROYECTO DE CAPACITACIÓN PARA PROFESORES: EDUCACIÓN DE RELACIONES RACIALES Y ÉTNICAS

FRANÇA, Cyntia Simioni'

\section{RESUMO}

O artigo apresenta parte de um projeto formativo sobre relações étnico-raciais, realizado por uma universidade e com professores de uma escola pública, no estado do Paraná. Buscou-se desconstruir estereótipos e preconceitos perpetuados no imaginário social em relação aos povos africanos e afro-brasileiros, construir relações mais solidárias e valorizar uma educação antirracista que problematiza as narrativas dominantes. Apesar das contradições da modernidade capitalista, o texto defende que ainda pode-se operar pelas brechas do pensamento hegemônico para que outras relações humanas possam ser construídas no presente, de modo que superemos o racismo e o mito da democracia racial.

Palavras-chave: Formação continuada, Diversidade, Educação das relações étnico-raciais (ERER).

\section{ABSTRACT}

The article is part of a training project on ethnic-racial relationships, carried out by a university and with professors from a public school in the State of Paraná, Brazil. The aim was to deconstruct stereotypes and preconceptions perpetuated in the society in relation with the African and Afro-Brazilian people, build more supportive relationships and to value a type anti-racist education that problematizes the dominant narratives. Despite the contradictions of capitalist modernity, the text is going to defend the fact that there is still a way to operate through the gaps of the hegemonic thought so that the other human relations can be built in the present, so that we could overcome racism and the myth of racial democracy.

Keywords: Online education, Diversity, Education of ethnic-racial relations.

\section{RESUMEN}

El artículo presenta parte de un proyecto formativo sobre relaciones étnico-raciales, realizado por una universidad y con profesores de una escuela pública del Estado de Paraná en Brazil. Se buscó desconstruir estereotipos y preconceptos perpetuados en el imaginario social en relación con los pueblos africanos y afrobrasileños, construir relaciones mas solidarias y valorizar una educación antirracista que problematice las narrativas dominantes. A pesar de las contradicciones de la modernidad capitalista, el texto defiende que aún se puede operar por las brechas del pensamiento hegemónico para que otras relaciones humanas puedan ser construidas en el presente, de modo que superemos el racismo y el mito de la democracia racial.

Palabras clave: Educación continua, Diversidad, Educación de las relaciones étnico-raciales.

\footnotetext{
${ }^{1}$ Universidade Estadual do Paraná - UNESPAR - Campo Mourão - Paraná - Brasil.
} 


\section{INTRODUÇÃO}

"Eu não consigo respirar".

George Floyd

Neste artigo $^{2}$ compartilho uma experiência de formação continuada de professores, desenvolvida no âmbito de um projeto de pesquisa, ensino e extensão, ocorrido em 2015, em parceria entre universidade e uma escola pública, na cidade de Londrina, no interior do estado do Paraná.

O projeto formativo focalizou as relações étnico-raciais, com a intenção de compreender a temática dentro de um processo histórico-cultural brasileiro e instigar a construção de práticas pedagógicas de resistência ao racismo e ao preconceito construído durante séculos no Brasil.

Embora o projeto foi desenvolvido há alguns anos, porém, o debate em torno da problemática da educação das relações étnico-raciais é latente nos dias de hoje, principalmente pelo fato do racismo estar naturalizado em nossa sociedade, seja nas relações de poder, econômicas, sociais e de gênero. Embora avançamos no entendimento de que a erradicação do racismo é um dever ético e político de toda a população brasileira e não apenas da população afro-brasileira, por outro lado, enfrentamos grupos políticos conservadores que estão no poder e continuam reforçando o mito da democracia racial e promovendo discursos negacionistas que disseminam que na sociedade brasileira não tem racismo e nem desigualdade racial entre brancos e negros. Inclusive o atual presidente da república dissemina por diferentes mídias sociais declarações racistas, endossadas por vários parlamentares, governadores e prefeitos do nosso país.

Mais do que nunca são necessários dispositivos legais, políticas afirmativas de igualdade racial, construção de projetos educacionais antirracistas que nos mobilize a uma mudança de pensamento e de práticas culturais. Acreditamos que a educação é capaz de "questionar e desconstruir os mitos de superioridade e inferioridade entre os grupos humanos que foram introjetados neles pela cultura racista na qual foram socializados" (MUNANGA, 2005, p. 17).

Entendemos que a escola é um lócus onde as práticas de desigualdade social, racial cultural e econômica são (re)produzidas e (re)inventadas (THOMPSON, 1981). É importante os professores entenderem a escola como um campo de tensão, conflitos e lutas

\footnotetext{
e a pedagogia como uma forma de política cultural voltada para um projeto de sociedade justa, igualitária, democrática e emancipatória. Isso significa movimentar valores, crenças e culturas consideradas como verdades e tencionar, através de práticas pedagógicas, a desconstrução de concepções colonialistas, racistas, conservadoras e excludentes, que banalizam e tornam insignificantes as práticas sociais, culturais e históricas seculares (PAIM, 2016, p.2)
}

Nesse sentido, acreditamos que projetos de formação de professores que têm como mote de reflexão a educação das relações étnico-raciais são fundamentais para superar o racismo e construir uma sociedade democrática antiracista em que todos possam respirar. Quantas vezes em nossas

\footnotetext{
${ }^{2}$ Uma versão reduzida e parcial desse projeto foi publicada em anais de eventos, apresentando apenas as linhas gerais da proposta formativa, porém para essa revista, o artigo apresenta sua versão completa (com todos os dados e análises finalizados) e o projeto de formação encontra-se concluído.
} 
salas de aula presenciamos os estudantes sufocados por práticas racistas? A última frase de George Floyd ${ }^{3}$ "eu não consigo respirar" é uma realidade de estudantes negros que enfrentam diariamente práticas racistas sufocantes tanto no espaço escolar como na sociedade brasileira.

\section{CONHECENDO O PROJETO}

Uma das inquietações iniciais da pesquisa foi construir uma proposta formativa significativa com os professores e tecida por relações dialógicas, interativas, coletivas e colaborativas (THOMPSON, 1981).

O projeto formativo foi uma pesquisa ação (ELLIOTT, 1998) desenvolvida em duas etapas: na primeira, os professores foram convidados, a participarem de um questionário com questões abertas e fechadas. As perguntas foram pautadas nos eixos temáticos: formação inicial e continuada, cotidiano escolar, metodologias de ensino e tecnologias da informação e comunicação no ensino. A segunda etapa foi elaborada uma proposta de formação, a partir das relações que estabelecemos com o espaço escolar e com os professores.

A primeira etapa do projeto foi importante para investigar as necessidades formativas dos professores que atuavam na escola, visando constituir espaços de formação. O projeto tinha na sua primeira etapa os seguintes objetivos específicos: 1) identificar as dificuldades e os anseios dos professores; 2) construir propostas de formação continuada ligadas às necessidades do cotidiano escolar que fizessem sentidos para todos os sujeitos participantes; e, 3) articular as atividades de pesquisa e práticas de ensino da universidade às atividades de ensino e pesquisa da escola pública que participou do projeto.

A ideia de formação defendida neste projeto é como um processo interior, vinculada às experiências vividas dos professores e amalgamada por diferentes saberes: pessoais, subjetivos, relativos. Saberes receptivos, atravessados pela abertura ao outro, em movimento e transformação e imbricados em uma trajetória dilatada de formação docente que abarca a longa duração. Formação como um processo contínuo que promove a emancipação dos sujeitos. (TARDIFF, 2014; GALZERANI, 2008)

Este projeto distancia-se de formação continuada que trazem leituras prontas e questões assentadas no olhar das culturas dominantes, pelo contrário, partimos dos problemas do cotidiano escolar e das necessidades dos docentes, rompendo com modelos que se pautam na reprodução de saberes, mas reconhecendo os professores como sujeitos produtores de conhecimentos históricos e educacionais. (CHERVEL, 1990; TARDIFF, 2002; FRANÇA, 2015)

Desenvolver o projeto formativo foi possível porque os professores na primeira etapa do projeto aceitaram voluntariamente responder o questionário que Ihes foi apresentado para podermos construir

\footnotetext{
${ }^{3}$ George Floyd era um homem negro de 46 anos, morto no último 25 de maio, após detenção policial na cidade americana de Minneapolis, no estado de Minnesota. Ele foi asfixiado por quase oito minutos após ter sido algemado e imobilizado pela polícia local e um dos policiais, que é branco, ajoelhou sobre o pescoço de Floyd e, com as mãos nos bolsos, posava para as câmaras de celular que filmavam Floyd agonizando e implorando pela mãe e por ar
} 
coletivamente uma formação de professores que partissem dos seus anseios, dificuldades e necessidades escolares.

Tivemos o retorno de cinquenta e seis (56) questionários respondidos pelos professores, porém foram entregues setenta e seis (76). As questões relacionadas acerca da necessidade de propostas de formação continuada puderam oferecer um panorama para desenvolver coletivamente o projeto formativo, conforme mostra o gráfico 1.

GRÁFICO 1- Temáticas sugeridas pelos professores para proposta de formação

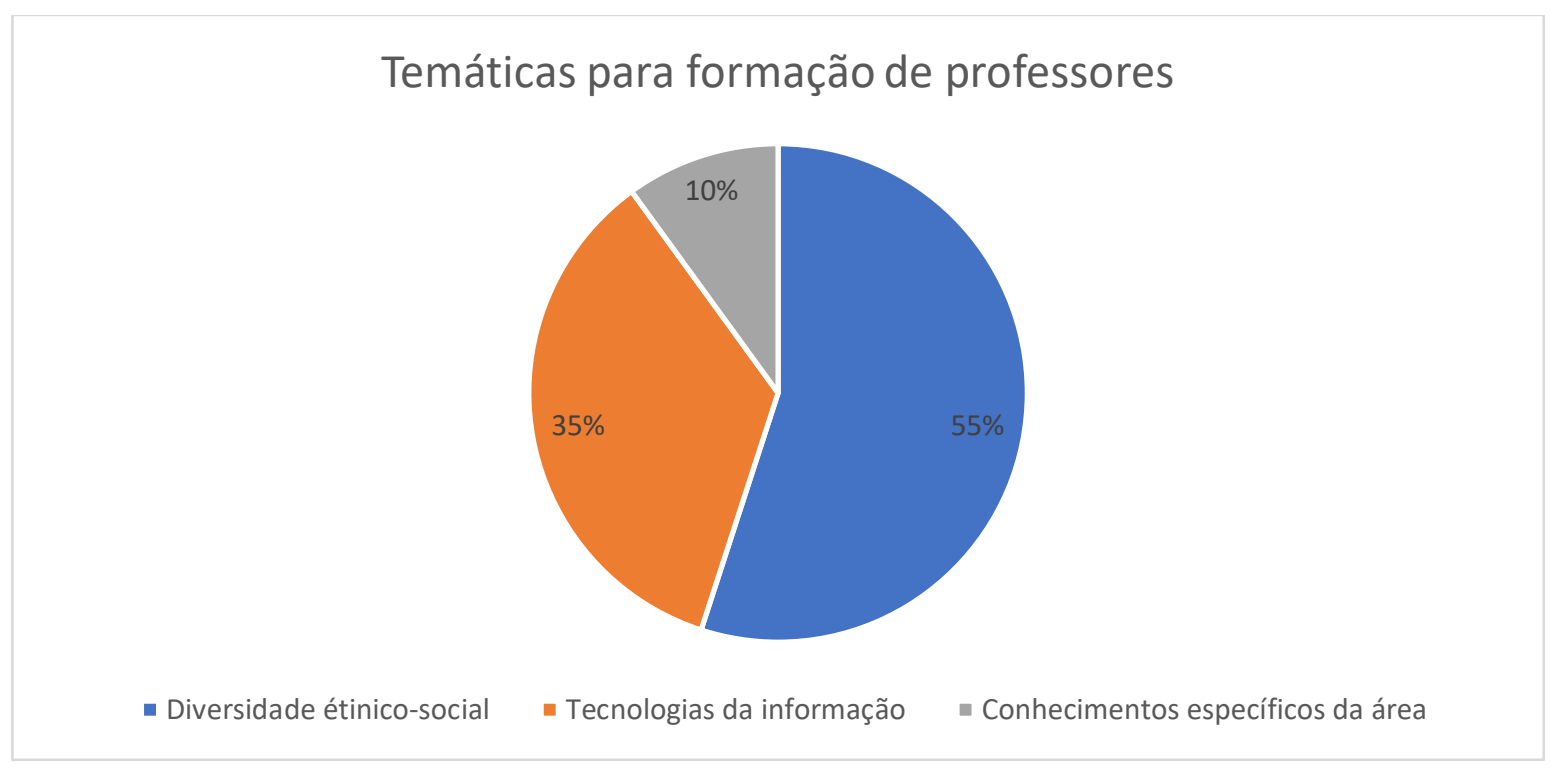

Fonte: dados da pesquisa (2015).

A maior parte das respostas dos professores (55\%) enfatizou o interesse em aprofundar o debate sobre a temática diversidade (diversidade étnico-racial). Enquanto 10\% apontaram questões voltadas para suas áreas específicas do saber e 35\% para temáticas que contemplassem o uso das tecnologias de informação e comunicação no ensino.

A proposta de formação desenvolvida na segunda etapa do projeto com os professores, foi com a temática "relações étnico-raciais", a qual será delineada neste artigo. O projeto de formação continuada foi colocado em ação, entre os meses de agosto a dezembro de 2015, em uma sala de recursos, dentro da própria escola pública, no período vespertino, com duração de quatro horas semanais.

A metodologia de trabalho escolhida para o desenvolvimento das atividades relacionada a temática da educação das relações étnico-raciais baseou-se na organização de oficinas, palestras, rodas de conversas, leitura de obras literárias, análises de legislação e outras atividades.

Nesses encontros, a participação inicial foi de trinta professores ${ }^{4}$ de diferentes áreas do conhecimento. $\mathrm{O}$ gráfico 2 , apresenta o perfil desses profissionais.

\footnotetext{
${ }^{4}$ Começamos em agosto o projeto formativo com 30 professores e encerramos em dezembro com a participação de 16 professores, a desistência foi acontecendo no decorrer do semestre, por conta da dificuldade em conciliar
} 
Gráfico 2- Perfil dos professores

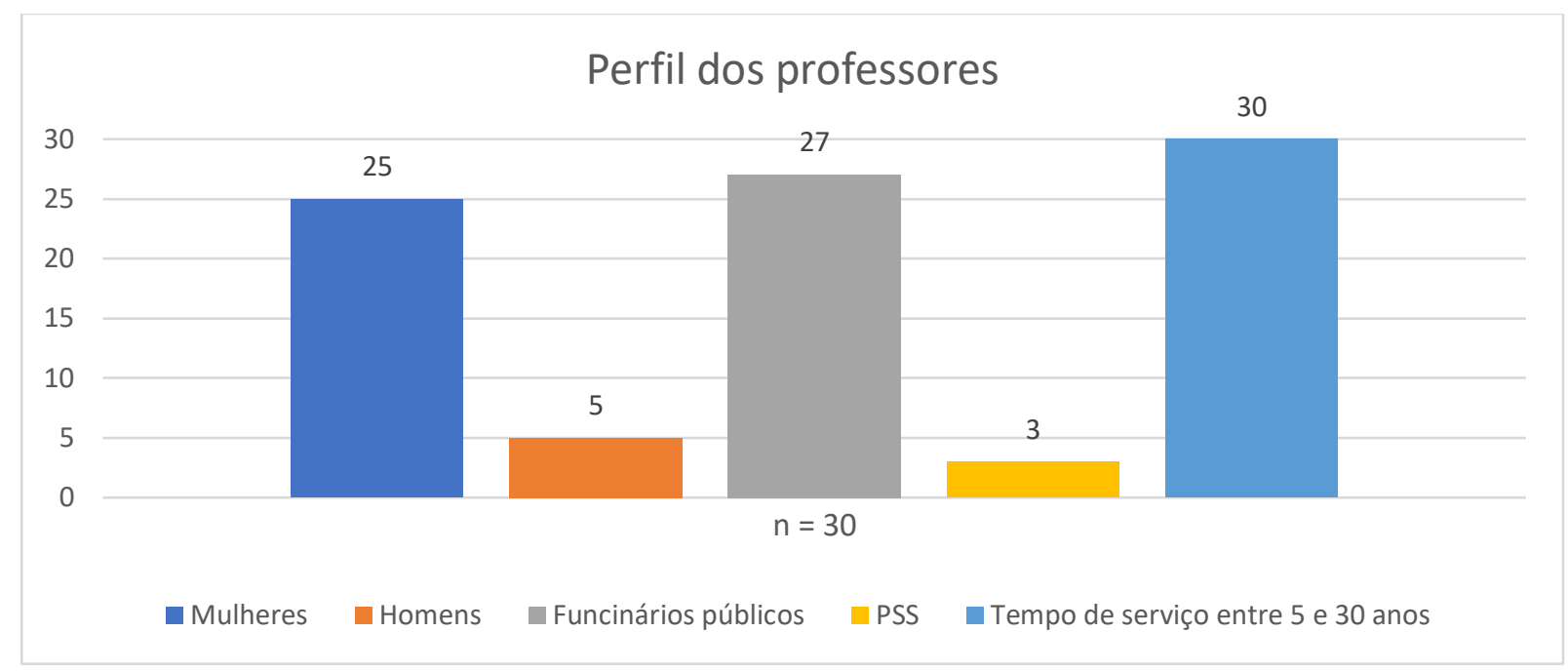

Fonte: dados da pesquisa (2015)

A maioria dos professores se constituía por mulheres. A respeito do tempo médio de serviço dos professores levantou-se um período de cinco a trinta anos de docência, sendo a maioria do quadro de funcionários públicos, do estado do Paraná.

Procuramos construir alternativas docentes face às contradições vivenciadas pelos professores da educação básica, principalmente, com seus alunos, no que tange aos relacionamentos conflituosos, sobretudo, àqueles ligados à intolerância às diferenças étnico-raciais, bem como a elaboração de práticas pedagógicas de resistência para a valorização da cultura afro-brasileira, superação do racismo e construção de relações sociais mais respeitosas entre os professores, alunos e comunidade escolar.

A formação de professores foi desenvolvida em quatro ciclo de debates com a intenção de compreender a temática dentro de um processo histórico-cultural brasileiro, mais do que isso, instigar práticas pedagógicas de resistência ao racismo e o preconceito construído durante séculos no Brasil.

\section{$1^{\circ} \mathrm{CICLO}$ DE DEBATES}

No primeiro ciclo de debates com os professores foi articulado as dimensões teóricas e práticas sobre as relações étnico-raciais.

Algumas temáticas escolhidas pelos professores foram: diversidade, preconceito, práticas racistas, movimentos sociais, ações afirmativas, mito da democracia racial, leis 10.639/03 e 11.645/08, com o intuito de forjar, o estabelecimento de relações mais solidárias, de respeito em relação ao outro bem como na construção de uma educação antirracista, no sentido de desconstruir narrativas étnico-

os seus horários com uma participação semanal durante todo esse período, doenças de alguns professores, dificuldade em realizar as leituras dos ciclos de debates, devido a carga horária excessiva de trabalho, sendo a maioria deles com 40 a 50 horas semanais e outros. 
raciais dominantes que omite e nega as contribuições de outros grupos étnicos, na tentativa de apagar as suas memórias e histórias. (GOMES; SILVA, 2002).

Buscamos no primeiro momento de diálogo focalizar os campos de luta, trazendo a importância das lutas coletivas dos movimentos sociais. Ainda, como uma das atividades propostas, decidimos identificar com os professores, os movimentos que engendravam essa luta. Vieram à tona em suas falas as ações dos movimentos negros, dos indígenas, das mulheres, das pessoas com deficiência e do movimento de Lésbicas, Gays, Bissexuais e Travestis (LGBT).

Focalizamos o debate sobre os movimentos sociais que lutam pelas causas dos povos afrobrasileiros para compreendermos junto com os professores, a relevância do surgimento de políticas de ações afirmativas na sociedade brasileira para as chamadas "minorias", aquelas entendidas como grupos que sofreram e ainda sofrem preconceito em nossa sociedade (GIDDENS, 2010; GOMES, $2015 ; 2017)$.

As ações afirmativas buscam minimizar a desigualdade, ou seja, oferecer um tratamento próprio para grupos minoritários, cuja particularidade ou diferença é travada historicamente de forma desigual. Sendo assim, uma das propostas da ação afirmativa é a de coibir a discriminação no presente, mas, sobretudo, eliminar os efeitos persistentes da discriminação do passado que tendem a se perpetuar em nosso país, por meio de práticas culturais e nos discursos sociais e políticos. Já que a igualdade e a liberdade nunca foram consumadas para todos que aqui vivem bem como as práticas discriminatórias e o tratamento desigual continuam ainda sendo predominante nas relações existentes na sociedade brasileira (GOMES, 2015).

Diante da discriminação e o preconceito gerado por vários séculos no Brasil, os movimentos sociais em prol das causas afro-brasileiras, por meio de intensas lutas conseguiram a aprovação de legislação que garante seus direitos e promove a igualdade de direito pela via de ações afirmativas. Uma das conquistas dos movimentos sociais negros foi o sancionamento da Lei 10.639/03, pelo presidente Luís Inácio Lula da Silva, em 2003, instituindo a obrigatoriedade do ensino de História da África e das culturas afro-brasileiras no currículo escolar, na rede de ensino particular e público no Brasil. Tal legislação foi modificada pela Lei 11.645/08 que inclui a obrigatoriedade do ensino de história indígena. O estudo da história da África, da história e da cultura afro-brasileiras foram reivindicações que sempre estiveram na pauta de prioridades do Movimento Negro (ALBERTI; PEREIRA, 2007).

Estes movimentos sociais entendem que as ações afirmativas ampliam os horizontes sociais no presente, à medida que abrem possibilidades de superação do racismo e do mito da democracia racial. E a escola é uma das instituições que contribui para a construção de representações positivadas dos afro-brasileiros e de uma educação que respeite e valorize à diversidade ${ }^{5}$ como um dos elementos constituintes de uma formação cidadã.

\footnotetext{
${ }^{5}$ Compreendemos que a diversidade é uma construção histórica, social, cultural e econômica das diferenças, constituídas nas relações sociais e de poder. Segundo Nilma Gomes $(2008 ; 2015)$ a sociedade em que vivemos é desigual, diversa nos seguintes aspectos: cultural, étnico, racial, de gênero e se constrói imbricada nas relações de poder, as quais hierarquizam e discriminam a diversidade.
} 
Após a lei 10.639/03 surgiram várias iniciativas de propostas de formação de professores sobre a educação das relações étnico-raciais, mas ainda assim, os projetos formativos oferecidos entre as universidades e as secretarias de educação não foram suficientes para que de fato fosse efetivada na prática essa ação afirmativa no espaço escolar, isso porque essa discussão ocupa um lugar secundário nos cursos de formação de professores. (GOMES, 2008)

É importante ressaltar também que o não cumprimento dos documentos oficiais criados e implementados por meio de intensas lutas políticas dos movimentos sociais, especialmente, aqueles relacionados às causas indígenas e afro-brasileiras, estão vinculados muitas vezes:

\begin{abstract}
a opções políticas não declaradas dos governantes e de demais segmentos da sociedade que se esforçam em manter o status quo brasileiro. Sendo assim, acreditamos e constatamos que os atuais modelos de gestão política fazem questão de reproduzir mecanismos de segregação racial concebidos desde a época do Brasil colônia, seja por meio da manutenção de certos privilégios direcionados a segmentos específicos da sociedade, ou da institucionalização do racismo, entre outras práticas escusas. (PINHEIRO; SANTANA; PAIM; 2017, p. 339-340)
\end{abstract}

Ainda que existam avanços com o surgimento das políticas públicas educacionais afirmativas, é importante tomar muito cuidado com as práticas de silenciamento, as relações de poder e guerras políticas que continuam dificultando a efetivação das ações afirmativas. Esse diálogo foi tensionado com as reflexões dos professores, no próximo ciclo de debates, a partir da leitura da referida Lei $10.639 / 03$

\title{
$2^{\circ} \mathrm{CICLO}$ DE DEBATES
}

Iniciamos esse percurso de debate sugerindo aos professores a leitura da Lei 10.639/036 , e, em seguida, mobilizamos as discussões com as ideias da historiadora Claudia Fortuna. Ela destaca que a legislação foge de alguns eixos argumentativos predominantes e compreende a existência de vários fios de avanços. O documento considera que o espaço escolar deve se posicionar politicamente, promover o exercício da criticidade sobre conceitos, ideias e comportamentos veiculados pela ideologia dominante bem como "mudanças dos discursos e os modos de se tratar pessoas negras. [...] a importância da sensibilidade e de uma consciência política e histórica da diversidade". (FORTUNA, 2005, p. 94)

Segundo Fortuna (2005), não se trata de mudar o viés etnocêntrico para outro, africano nesse caso, mas sim de dilatar a acepção de currículo. Além disso, exige repensarmos as relações étnicoraciais de forma ampliada, como uma mudança de mentalidade, a fim de que a História dos povos afrodescendentes se articule com as dimensões temporais: passado, presente e futuro, no âmbito das experiências nas diferentes realidades do povo negro.

O passado dos povos afro-brasileiros durante séculos foi ensinado nas escolas como homogêneo, com o intuito de modelar um cidadão patriótico, bem como manter o prestígio das

\footnotetext{
${ }^{6}$ Apesar da Lei $10.639 / 2003$ ter sido modificada pela Lei $11.645 / 2008$, estamos dialogando com a primeira, tendo em vista a centralidade que ela ocupa na reflexão proposta neste projeto, e por referência às Diretrizes correlatas à lei que fomentam as análises.
} 
personalidades da nossa história que ficavam limitados à elite brasileira branca. Neste viés, os alunos sempre aprendem que o povo brasileiro é constituído por brancos descendentes de portugueses, índios e negros, predominando aquele pensamento da "ausência de preconceitos raciais no interior de uma sociedade sem conflitos. Na constituição desta memória histórica, aos negros cabem poucas páginas, ora como escravo, ora como vencido, ora com sua cultura transformada em folclore" (FORTUNA, 2008, p. 52).

É urgente não aceitar as culturas cristalizadas no tempo e no espaço ou os modos de mantêlas intactas ao longo de várias gerações. Pensar a diversidade cultural brasileira é considerar os intercâmbios culturais, com o intuito de evidenciar as experiências negras no país. (ABREU; MATTOS, 2008)

Sendo assim, as problemáticas levantadas com os professores foram: como é possível estimular a convivência e a tolerância interculturais sem pensar em mestiçagens e trocas, especialmente culturais, mesmo que agora no plural? O que deve significar a noção de pluralidade cultural quando pensada na escola? (ABREU; MATTOS, 2008)

Essas questões estimularam a tessitura de outros fios de conversas, enverendando o diálogo com os professores sobre a problematização do conceito de cultura e como temos entendido essa concepção na relação como nossas experiências do vivido.

O diálogo com os professores foi fomentado a partir do entendimento de cultura "como processo, e as identidades coletivas como construções culturais, por isso históricas e relacionais" (ABREU; MATTOS, 2008, p. 41), o que levou à preocupação com a construção "historicamente engendrada das "fronteiras" entre os sujeitos, das hierarquizações, dos apagamentos ou da negação do outro e, certamente, das resistências, percebidas também pelo viés da negociação e da ressignificação". (CUNHA, 2016, p.86) Entendemos que as culturas dos afro-brasileiros são constituídas na "relação com outros grupos étnico-raciais e culturais que constroem suas identidades cotidianamente, reelaborando costumes em meio a tensões e a conflitos" (CUNHA, 2016, p.86).

Para que os professores compreendessem essa construção histórica, relacional, tensa e dinâmica entre as diferentes culturas, trouxemos para alinhavar os fios de conversas dos professores, a acepção de cultura do historiador inglês Edward Palmer Thompson (1998). Para o autor, a cultura é um conjunto de significados partilhados e construídos pelos homens para explicar o mundo. Ela não é pensada apenas como expressão da sociedade, mas também instituinte da esfera social. (THOMPSON, 1981; 1998).

O filósofo alemão Walter Benjamin (1985; 1987) também ajudou nessa reflexão ao explicar a cultura a partir da acepção de visões de mundo e sensibilidades. O filósofo contribuiu com seu pensamento para compreendermos como acontecem as relações entre os diferentes sujeitos em uma sociedade capitalista, competitiva e excludente que promove o desenraizamento dos sujeitos de suas histórias e a separação das suas experiências vividas.

A historiadora Marcia Bichara (2005), a partir do pensamento benjaminiano, ressalta a importância de entender o preconceito e discriminação articulados aos preceitos da modernidade capitalista. Para Marisa Vorraber Costa (2204, p. 385), a "modernidade gerou variedades próprias de racismo, nas quais as culturas não-ocidentais frequentemente foram vistas como obstáculos ao 
desenvolvimento e ao progresso e passaram a ser vistas como anti-modernas". É no seio da modernidade capitalista que o mito da democracia racial ganha força e se dissemina em nosso país, por meio de inúmeros discursos colonialistas, racistas e excludentes. Essas questões passaram a ser problematizadas no próximo ciclo de debates.

\section{$3^{\circ} \mathrm{CICLO}$ DE DEBATES}

Iniciamos o diálogo com os professores refletindo sobre o mito da democracia racial com o intuito de desconstruí-lo. Quando tratamos sobre a questão do mito da democracia racial, entendemos que ele perpetua a ideia do negro ainda como escravo (mercadoria/inferior), visão que contribui para manter a hierarquia da convivência e perpetuar o preconceito entre as pessoas. Mesmo com mudanças no sistema político e social brasileiro, ainda permanece no imaginário coletivo o passado escravocrata, principalmente, na mentalidade daqueles que determinam as relações de poder. Ou seja, embora os negros não sejam mais escravos, ainda continuam, para as ideologias dominantes, vistos como seres "inferiores".

A permanência das estruturas tradicionais é uma anomalia da sociedade, pois o preconceito e a discriminação racial perpetuam a desigualdade racial de forma incompatível com o desenvolvimento humano. Além disso, promove uma contradição com os ideais democráticos, pois mesmo com o fim da escravidão, o preconceito e a discriminação racial não desapareceram. O preconceito é a manifestação do mito da democracia racial, é escamoteado para continuar a preservar o "passado no presente. Incompatível com os ideais democráticos da nova sociedade e com o desenvolvimento do regime de classes, desprovido de função aparente, o preconceito passa a ser negado, relegado ao inconsciente" (VERTUAN, p. 107, 2007).

Os diálogos sobre o mito da democracia racial propiciaram os professores contarem nas rodas de conversas, que, muitos alunos assumem outras identidades, para não passar por constrangimentos entre os colegas. Durante as nossas falas, destacamos o quanto os movimentos sociais são fundamentais para os mecanismos de luta, preservação dos direitos sociais e a busca da igualdade. Retomamos a questão de que Movimento Negro no Brasil e o quanto as Ações Afirmativas se configuram enquanto políticas públicas fundamentais para o nosso país, já que, infelizmente, a discriminação e o preconceito no Brasil é negado ou invisível pela ideia do mito da democracia racial, inclusive no espaço escolar.

Na escola são (re) produzidas e reinventadas práticas de desigualdades racial, social, cultural, religiosa e econômica. Por isso, entendemos a importância de problematizar os processos históricos geradores de preconceitos e transformar esse cenário construído e mantido há séculos no Brasil.

Ao encontro dessa reflexão, realizamos a leitura de um fragmento de jornal que conta sobre uma pesquisa-ação, desenvolvida em escolas, na cidade de São Paulo, pela pesquisadora Ana Maria Niemeyer. Ela relata que muitos professores negam a existência do racismo e que existe muita desinformação dos educadores a respeito da temática. Muitas vezes, diante de práticas discriminatórias, os professores ficam emudecidos porque desconhecem os modos de "identificar 
aquela atitude e, portanto, como discuti-la com a classe. Outras vezes se omitem porque não estão acostumados a pensar no significado de comportamento como esses na autoestima de seus alunos. Também existem aqueles que se calam porque são racistas. E aqueles que se manifestam pelas mesmas razões". (NIEMEYER, 2002, pp. 46-47)

Esse relato de Niemeyer foi impactante para os professores que passaram a relacionar com as suas experiências escolares e a pensar em suas práticas de ensino bem como nas diretrizes para as relações étnico-raciais (BRASIL 2004). Diversas narrativas dos professores vieram à tona, algumas corroboraram com a pesquisa de Niemeyer (2002) e outras negaram essas situações em seu cotidiano escolar. Nesse sentido, movimentamos as diferentes visões de mundo dos professores e tensionamos as acepções colonialistas, racistas, excludentes e negacionistas.

Ainda nesse calor de reflexões, alguns professores destacaram que reconhecem e questionam: 1) a presença marcante de um currículo predominantemente assentado em visão eurocêntrica; 2 ) livros didáticos com a maioria dos temas privilegiando estudos das questões europeias em detrimento à história e culturas africanas e afro-brasileiras 3) a necessidade de uma formação em História e Cultura Africana e Afro-Brasileira que ofereça subsídio teórico-metodológico para o desenvolvimento de práticas pedagógicas a contrapelo das tendências dominantes.

Com o intuito de superar os problemas elencados no cotidiano escolar, os professores foram instigados a pensar: Será possível ir ao encontro do que foi esquecido ou apagado da historiografia dominante?

A partir, dessa questão problematizadora, desdobraram-se debates com os professores, aproximando às ideias do filósofo alemão, Walter Benjamin, (1985, p. 224-225). O autor nos inspira a despertar no presente as "centelhas da esperança", visto que nem os mortos "estarão em segurança se o inimigo vencer. E esse inimigo não tem cessado de vencer". O autor insiste sobre os ancestrais vencidos, pois considera que não há luta pelo futuro sem memória do passado, a memória viva e concreta dos ancestrais martirizados. A rememoração aqui é a energia para as lutas do presente. $E$ tais lutas questionam as "vitórias históricas dos vencedores, enfraquecendo o poder dos opressores, tanto do passado como dos tempos atuais". (FORTUNA, 2008, p. 56).

A história da sociedade brasileira não será redimida se continuar com a manutenção do olhar da matriz cultural eurocêntrica, colonialista, racista, por isso, é possível a reescrita de outras narrativas históricas que não seja pela ótica do colonizador.

Para que essa história seja libertada e/ou arrancada do conformismo, urgentemente a história tem que ser escovada a "contrapelo" das tendências das ideologias dominantes, emprestando as palavras de Walter Benjamin. É necessário repensar a sociedade em um contexto mais amplo, em relação ao passado, presente e futuro. Isso requer debruçar sobre o passado como uma necessidade de escutar as "vozes silenciadas", o voltar ao passado não apenas para conhecê-lo tal como meramente os fatos aconteceram, mas, para agir no presente. (BENJAMIN, 1985)

Benjamin aposta que na rememoração os mortos, os esquecidos, os que foram apagados da história, são redimidos quando alguém os traz à tona pela reconstrução do vivido no ato rememorativo (PAIM, 2005). A rememoração na perspectiva benjaminiana busca outro porvir. Esse é o apelo de 
Walter Benjamin (1985), juntar os "cacos, os estilhaços, e as ruínas" produzidos pelas catástrofes do passado a fim de reconstituir o que foi arruinado e apagado pelas ideologias dominantes.

Em diálogo com Benjamin (1985;2007), no quarto ciclo de debates, desenvolvemos práticas de rememoração com os professores reunindo os cacos do passado, redimensionamos o presente e com vistas a construção de "outros" futuros.

\section{$4^{\circ} \mathrm{CICLO}$ DE DEBATES}

Neste ciclo, realizamos rememorações coletivas a partir das seguintes questões propulsoras: Como percebemos nossos alunos? Temos alunos afrodescendentes? Como nos enxergamos na relação com os alunos? Quantas vezes por dia presenciamos atitudes preconceituosas em nossa sala de aula? O que fazemos diante de práticas discriminatórias no espaço escolar? Temos nos preocupado com a pluralidade étnico-racial na escola?

Foi incentivada uma escavação de camadas de tempo e de memórias (BENJAMIN, 1985) a partir de lugares da escola, das pessoas que circulam esse espaço e das práticas culturais cotidianas, ou seja, no diálogo com os sujeitos que constituem e são constituídos no espaço escolar (THOMPSON, 1988).

Acreditamos que a educação das relações étnico-raciais pelo viés do pensamento benjaminiano

requer pensar alternativas pedagógicas em que professores e alunos são incentivados a recuperar a capacidade de deixar rastros, de imprimir marcas e ser autores. Significa a possibilidade de ver em cada adulto, jovem e criança, a sua história. A escola necessita encontrar a identidade narrativa, o que requer abrir espaço (na formação e nas diversas modalidades de gestão) para as experiências dos sujeitos que fazem a prática, para que resignifiquem a história contada e atribuam ou encontrem outros sentidos (KRAMER, 2009, p. 300).

O trabalho com práticas de rememoração coletiva foi importante para os professores reelaborarem outros sentidos sobre as suas práticas educacionais, com o intuito de percebermos o apagamento do outro (aluno, pais, comunidade, equipe pedagógica), os estereótipos no livro didático e de se pensar em propostas de materiais didáticos para uma educação das relações étnico-raciais, as hierarquizações dos saberes e sujeitos, e/ou silenciamentos das culturas e a reconstrução de outros modos de nos relacionarmos no presente.

Benjamin (1985) nos ajuda a compreender a educação das relações étnico-raciais como história aberta, espaço de diálogo de diferentes saberes (experienciais, pedagógicos, historiográficos, educacionais) e conhecimentos (científicos e escolares), em detrimento à reprodução das ideologias dominantes.

Ao assumirmos a acepção benjaminiana de história, distanciamos de uma perspectiva de história linear, progressista e homogênea e abrimos para uma compreensão de passado como algo 
que não está pronto, mas está à espera de nós professores buscarmos outras memórias, histórias e a reconstrução de outras narrativas históricas.

Esse percurso de diálogo buscou a transformação do presente por meio de práticas de rememoração, estimuladas pela literatura. O livro escolhido pelos professores para leitura foi "Menina Bonita do Laço de Fita" (2001), da autora Ana Maria Machado.

A leitura dessa obra literária despertou nos professores diferentes sensibilidades (GAY, 1988) e contribuiu não simplesmente ao entendimento da narrativa literária, mas instigou os professores construírem mudanças no presente, através da construção de propostas pedagógicas de resistências em sala de aula, no sentido de valorizar a presença dos povos africanos na sociedade brasileira. Práticas de resistências (THOMPSON, 1981), sobretudo, para desenraizar os preconceitos cristalizados no imaginário popular da sociedade brasileira.

Das inúmeras propostas pedagógicas de resistências construídas pelos professores, trazemos aqui as bonecas africanas. A partir da sugestão de um dos professores, decidimos a realização de uma oficina para confeccionar as bonecas africanas Abayomi, símbolo de resistência, tradição e universo feminino e refletimos teoicamente esses conceitos.

Por fim, construímos coletivamente algumas propostas pedagógicas para os professores realizarem com seus alunos em sala de aula. Escolhemos para tratar nesse artigo, uma atividade que contemplava diferentes áreas do conhecimento, o "Mancala". É um jogo conhecido por todos os povos africanos e foi introduzido no Brasil durante o período da escravidão. Diferente da maioria dos jogos de tabuleiro que pretendem acabar com o adversário, ao contrário, este focaliza a estratégia, bem como instiga a ideia de semear e colher. 0 jogo mancala apresentado na figura 1 , possibilitou discutir o princípio da história e cultura africana: a unidade e a diversidade. As variadas regras, lendas e as múltiplas formas de tabuleiros contribuíram para desenvolver a ideia da diversidade, enquanto a semeadura, a colheita e a partilha foram articuladas ao pensamento de recomeço (unidade).

Foto 1- Alunos construindo o jogo mancala 


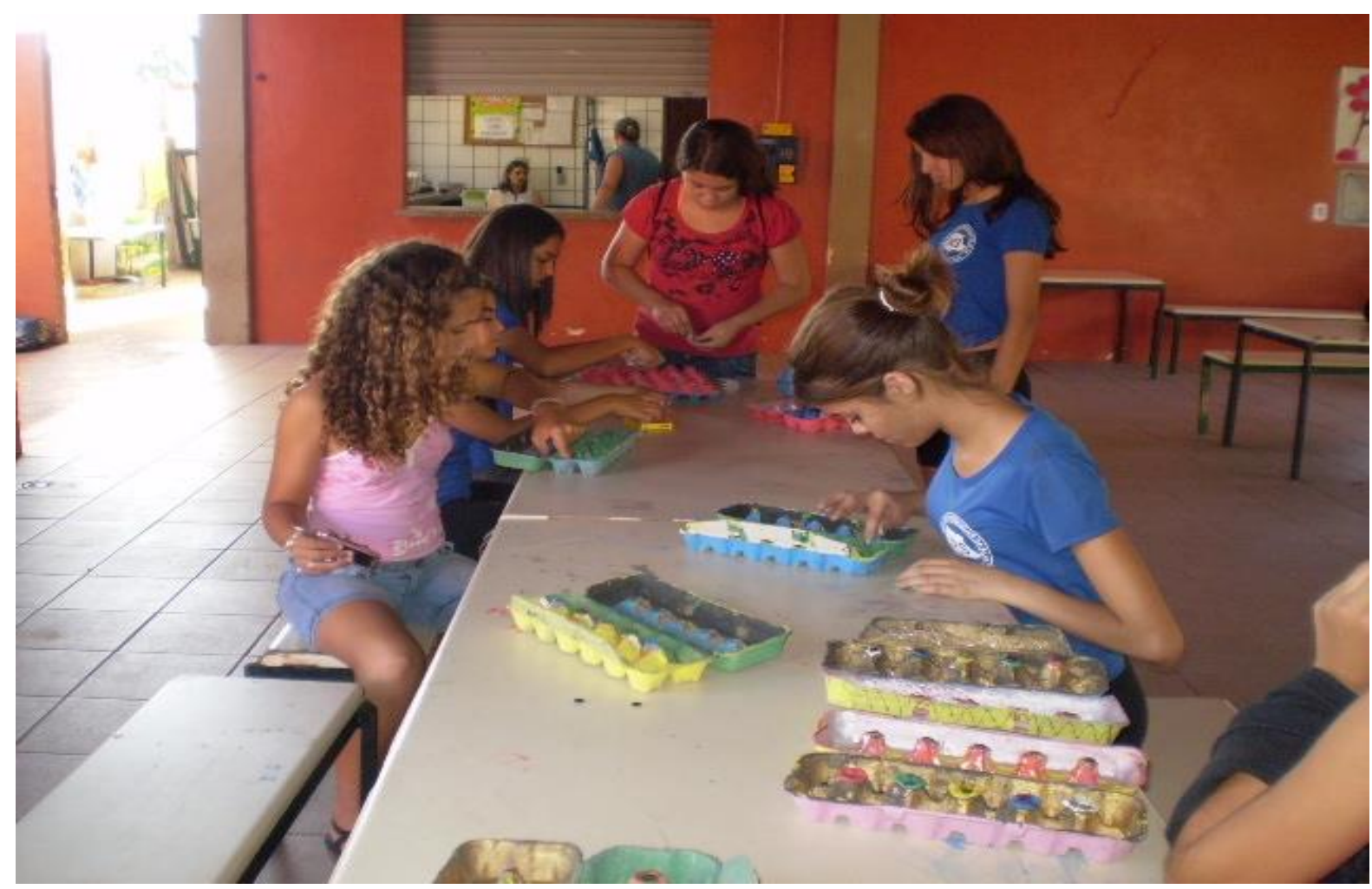

Fonte: autora (2015).

O jogo baseia-se essencialmente na distribuição de sementes em cavidades, denominadas também de casas, covas e/ou buracos existentes nas laterais de um tabuleiro. Com relação a este jogo:

\begin{abstract}
É condição que nestas cavidades sejam distribuídos o mesmo número de sementes, podendo a quantidade colocada em cada cavidade variar entre as regiões, de acordo com as regras estabelecidas, mas antes de iniciar o jogo as cavidades devem estar semeadas com a mesma quantidade de semente. As jogadas consistem em retirar todas as sementes de uma determinada cavidade do próprio território e semear as cavidades seguintes, a semeadura inclui as casas pertencentes ao jogador como as cavidades do parceiro de jogo. Porém, não pode ser feita uma jogada a partir do território alheio. Somente deve ser distribuída uma semente por vez em cada casa. (SILVA E SILVA, 2011, p.7)
\end{abstract}

O mancala é um jogo que estimula exercícios de observação, de análise e de reflexão para o desenvolvimento de estratégias e táticas de ação. "A noção de ganhar-perder obtém outra lógica: a do recomeço, da generosidade, da vida. [...] Como artifício tático utiliza o sistema de semeadura e partilha". (SILVA E SILVA, 2011, p. 8)

Por que escolhemos os jogos de semeaduras da África para encerrarmos essa experiência singular de formação de professores? A escolha do jogo africano está ligada com a proposta inicial do projeto formativo, desenvolver reflexões que acolham as diferentes vozes dos professores, que não os distanciem de suas experiências, que priorize o diálogo com o outro e que o respeito às diferenças culturais, étnicas, sociais, seja um princípio ético-responsivo de todos. Portanto, o jogo mancala deixa como ensinamento a ideia de viver em partilha, de um mundo com pessoas mais generosas e nos 
inspira a plantar essas sementes na escola para que, no futuro, possamos nos relacionar e viver em uma sociedade mais justa e menos desigual.

\section{ALGUMAS SEMENTES PLANTADAS}

Ao final dos quatro ciclos de debates realizados em diálogo com as experiências dos professores buscamos desconstruir os estereótipos e os preconceitos construídos e perpetuados no imaginário social em relação aos povos africanos e afro-brasileiros.

Nessa proposta formativa, percebemos a potencialidade de nos reconhecermos como sujeitos históricos para operar a contrapelo de uma sociedade, colonial, racista, patriarcal e excludente, visto que a escola, pode ser um espaço de reprodução de ideologias dominantes, mas também um lócus de mudanças, no que tange às práticas preconceituosas e racistas, e isso, depende de nós. Apesar das contradições da modernidade capitalista, ainda, podemos operar pelas brechas do pensamento hegemônico para que outras relações humanas possam ser construídas no presente de modo que supere o racismo e o mito da democracia racial.

Uma das intenções dessa proposta formativa foi instigar os professores envolvidos durante os ciclos de debates a deslocar os olhares acerca de suas práticas culturais cotidianas na relação com seus alunos no espaço escolar. Foi perceptível na fala de alguns professores que muitas vezes passava despercebido as práticas racistas que aconteciam no espaço escolar e se preocuparam com suas atitudes e suas práticas de ensino bem como indagaram as relações que eles têm construído em sala de aula com os alunos. Esse diálogo não foi desprovido de tensões e embates das diferentes visões de mundo que cada professor trazia consigo. Enfrentamos dificuldades ao promover esses diálogos, pois as contradições e as visões monolíticas estiveram presentes nas falas dos professores, mas conseguimos plantar algumas sementes que no futuro serão colhidas.

Vivemos em um tempo sombrio de embotamento das experiências vividas dos professores, do diálogo, da partilha e do encontro bem como tentativas acirradas de apagamento das memórias e histórias dos povos africanos e afro-brasileiros, portanto, projetos formativos como esse podem ser estimulados, com o intuito de fortalecer a dimensão humana do professor, ampliar a noção de sujeito histórico para a construção de práticas de ensino dissonantes das tendências racistas prevalecentes na modernidade bem como para a construção de relações sociais respeitosas e dialógicas no espaço escolar.

É preciso mais projetos de formação de professores que reflitam sobre a educação das relações étnico-racial para que os planos de aula, projetos políticos pedagógicos, práticas de ensino não perpetuem a matriz colonial eurocêntrica, autoritária e excludente. Quantos saberes e fazeres da cultura dos povos afro-brasileiros ainda estão fora dos muros escolares, dos espaços universitários, dos cursos de formação de professores, das produções dos livros didáticos, da base nacional comum curricular e da divulgação histórica nas redes sociais? Enfim, fica a pergunta para continuar a reflexão: Até quando vamos deixar que práticas racistas nos espaços escolares não deixem os estudantes respirar? 


\section{REFERÊNCIAS}

1. ABREU, Martha; MATTOS, Hebe. Em torno das "Diretrizes curriculares nacionais para a educação das relações étnico-raciais e para o ensino de história e cultura afro-brasileira e africana": uma conversa com historiadores. Estudos Históricos, Rio de Janeiro, v. 21, n. 41, p. 5-20, jan./ago. 2008.

2. ALBERTI, Verena \& PEREIRA, Amilcar A. (org). Histórias do movimento negro no Brasil: depoimentos ao CPDOC. Rio de Janeiro, Pallas; CPDOC -FGV, 2007.

3. BENJAMIN, Walter. "Obras Escolhidas, V. I, Magia e técnica, arte e política, trad. S. P. ROUANET, São Paulo: Brasiliense, 1985.

4. BENJAMIN, Walter. Passagens. Belo Horizonte: Ed. da UFMG/Imprensa Nacional do estado de São Paulo, 2007.

5. BICHARA, Márcia Regina Poli. Focando a discriminação em sala de aula: memória, história e ensino de história. (Dissertação de Mestrado) Campinas, SP: 2005.

6. BRASIL. Ministério da Educação/Secretaria de Educação Fundamental. Parâmetros Curriculares Nacionais/ Temas Transversais. 1998.

7. BRASIL/Secad. Diretrizes curriculares nacionais para a educação das relações étnico-raciais e para o ensino de história e cultura afro-brasileira e africana na educação básica. 2004.

8. BRASIL. Parâmetros Curriculares Nacionais: pluralidade cultural, orientação sexual. MEC/SEF, 1997.

9. BRASIL. Lei no 10.639, de 9 de janeiro de 2003. Diário Oficial [da] República Federativa do Brasil. Brasília, DF, 92003.2 jan. Disponível em: <http://www.planalto.gov.br/ccivil_03/leis/2003/L10.639.html>. Acesso: jan.2019.

10. BRASIL. Lei $\mathrm{n}^{\circ} 11.645$ de 10 de março de 2008 . Disponível em: http://www.planalto.gov.br/ccivil_03/_Ato2007-2010/2008/Lei/L11645.htm

11. BUENO, Maria de Fátima Guimarães. A história da educação: a cidade, a arquitetura escolar e o corpo. Cadernos do CEOM, a. 21, n. 28, jun., 2008, p. 243-278. 
COSTA, Marisa Vorraber. Diversidade, multiculturalismo e diferença: uma conversa com professores e professoras. In: Barbosa, Raquel Lazzari Leite. (Org). Formação de Educadores Trajetórias e Perspectivas. São Paulo: Editora da UNESP, 2004.

14. CUNHA, Nara Rúbia de Carvalho. Das muitas cores de uma cidade: o projeto Roxo-Rei e as memórias de negros e de índios na paisagem de Ouro Preto. Grifos (UNOESC), v. 25, p. 81-95, 2017.

15. ELLIOTT, John. Recolocando a pesquisa-ação em seu lugar original e próprio. In: GERALDI, Corinta Maria Grisolia, FIORENTINI, Dario e PEREIRA, Elisabete Monteiro de Aguiar (Orgs.). Cartografias do Trabalho Docente: professor(a)-pesquisador(a). Campinas: Mercado das Letras, 1998.

16. FORTUNA, Claudia Regina Alves Prado. Fios de histórias e memórias dos africanos e afrodescendentes no Brasil moderno. Por uma educação política dos sentidos. Campinas, Tese de Doutorado. Faculdade de Educação. 2008

GALZERANI, Maria Carolina Bovério; PARDO, Maria Benedita Lima; LOPES, Amélia (Orgs.). Una "nueva" cultura para la formación de maestros: es posible? Porto, Portugal: Ed. Livipsic/AMSEAMCE-WAER, 2008a. Paulo: Companhia das Letras, 1988.

19. GOMES, Nilma Lino. Cotas para a população negra e a democratização da universidade pública. In: PEIXOTO, Maria do Carmo Lacerda (Org.). Universidade e democracia. Belo Horizonte: Editora UFMG, 2004, p.45-56.

GOMES, Nilma Lino. Diversidade e currículo. In: BEAUCHAMP, Jeanete, PAGEL, Sandra Denise. Indagações sobre o currículo - diversidade e currículo. Brasília: Ministério da Educação, Secretaria da Educação Básica, 2008. 48 p. GOMES, Nilma Lino. Diversidade e afrodescendência: mediações, interações e (re)conhecimento. Comunicação em Foco, v.18, n.26, p.277-280, 2015. GOMES, Nilma Lino. Políticas para a diversidade. Sapere Aude.v.8. n.15.2017. Formação de Professores. Belo Horizonte: Autêntica, 2002. 
24. GIDDENS, Anthony. Sociologia. Lisboa, Fundação Calouste Gulbenkian. 2010.

25. MACHADO, Ana Maria. Menina Bonita do Laço de Fita. llustração de Claudius, São Paulo, Ática, 2001.

26. MUNANGA, K. Superando o racismo na escola. 2 ed. MEC/Secad, 2005.

27. NIEMEYER, A. M. "O silenciamento do 'negro' na auto-identificação étnica: um estudo com adolescentes de duas escolas públicas paulistanas". NUDECRI/UNICAMP -Campinas, v. 8, p. 4372, 2002.

28. PAIM, Elison Antonio. Memórias e experiências do fazer-se professor. Tese (Doutorado) Faculdade de Educação, Universidade Estadual de Campinas, Campinas 2005.

29. PAIM, Elison Antônio. Para além das leis: o ensino de culturas e histórias africanas, afrodescendentes e indígenas como decolonização do ensino da história. In: MOLINA, Ana Heloisa, FERREIRA, Carlos Augusto Lima (Org.). Entre textos e contextos: caminhos do ensino de História. Curitiba: editora CRV, 2016. 526 p.

30. PEREIRA, Júnia Sales. Reconhecendo ou construindo uma polaridade étnico-identitária? Desafios do ensino de história no imediato contexto pós-lei 10.639. Estudos Históricos, Rio de Janeiro: Ed. FGV, n.41, p.21-43, 2008.

31. PINHEIRO, P. M.; SANTANA, T. O.; PAIM, E. A. Narrativas de professores/as sobre a abordagem das temáticas indígena nas aulas de história. In: Elison Antonio Paim. (Org.). Patrimônio Cultural e Escola: entretecendo saberes. 1ed.Florianópolis: NUP/CED/UFSC, 2017, v. 1, p. 335-359.

32. SILVA, E. J; SILVA, M. C. P. Aprendizagem da História da África a partir dos Jogos Mancala. Anais do XXVI Simpósio Nacional de História - ANPUH, jul. 2011. São Paulo.

33. TARDIFF, Maurice. Saberes docentes e formação profissional. Petrópolis: Editora Vozes, 2014.

34. THOMPSON, Edward Palmer. Costumes em comum: estudos sobre a cultura popular tradicional. São Paulo-SP: Companhia das Letras, 1998.

35. THOMPSON, Edward Palmer. A miséria da teoria ou um planetário de erros. Rio de JaneiroRJ: Zahar, 1981 
36. VERTUAN, Maria José dos Santos. História Afro-Brasileira e Africana nas Escolas. In: Cultura Afrobrasileira- Construindo novas histórias, Elena Maria Andrei e Frederico Augusto Garcia Fernandes, Caderno Uniafro 2, Londrina- Idealiza Gráfica e Editora, 2007.

\section{Cyntia Simioni França}

Doutora em Educação pela Universidade Estadual de Campinas (UNICAMP). Membro do grupo Kairós: Educação das Sensibilidades, História e Memória vinculado ao CMU (Centro de Memória/UNICAMP), membro do Grupo de Estudos e Pesquisas em Educação Continuada-GEPEC - Faculdade de Educação-UNICAMP. Docente do programa de Mestrado em História Púbica da Universidade Estadual do Paraná (UNESPAR). Docente do PROFHISTÓRIA UNESPAR e professora do curso de licenciatura em História. Dedico às seguintes temáticas: produção de conhecimentos históricos e educacionais, ensino de história, estágio curricular, livros didáticos, formação de professores, práticas de memórias e narrativas na interface com a História Pública.

\section{Como citar este documento:}

FRANÇA, Cyntia Simioni. A TESSITURA DE UM PROJETO DE FORMAÇÃO DE PROFESSORES: EDUCAÇÃO DAS RELAÇÕES ÉTNICO-RACIAIS. Reflexão e Ação, Santa Cruz do Sul, v. 29, n. 1, p. 50-67, jan. 2021. ISSN 1982-9949. Acesso em:_. doi: http://dx.doi.org/10.17058/rea.v29i1.13117 